\title{
Angiotensin-(3-4) modulates the overweight- and undernutrition- induced ACE2 downregulation in renal proximal tubule cells: implications for COVID-19?
}

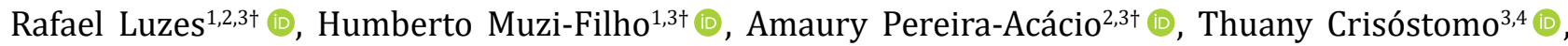 \\ Adalberto Vieyra ${ }^{1,2,3} *_{(0)}$ \\ ${ }^{1}$ Carlos Chagas Filho Institute of Biophysics, Federal University of Rio de Janeiro, 21941-170 Rio de Janeiro, Brazil \\ ${ }^{2}$ Graduate Program of Translational Biomedicine/BIOTRANS, Unigranrio University, 25071-202 Duque de Caxias, Brazil \\ ${ }^{3}$ National Center of Structural Biology and Bioimaging/CENABIO, Federal University of Rio de Janeiro, 21941-902 Rio de \\ Janeiro, Brazil \\ ${ }^{4}$ Leopoldo de Meis Institute of Medical Biochemistry, Federal University of Rio de Janeiro, 21941-902 Rio de Janeiro, Brazil
}

${ }^{\dagger}$ These authors contributed equally to this work.

*Correspondence: Adalberto Vieyra, Carlos Chagas Filho Institute of Biophysics, Federal University of Rio de Janeiro, 373 Carlos Chagas Filho Ave, Building G, Lab G1-037, University City, 21941-902 Rio de Janeiro, Brazil. avieyra@biof.ufrj.br

Academic Editor: Carlos M. Ferrario, Wake Forest School of Medicine, USA

Received: December 19, 2020 Accepted: March 24, 2021 Published: April 30, 2021

Cite this article: Luzes R, Muzi-Filho H, Pereira-Acácio A, Crisóstomo T, Vieyra A. Angiotensin-(3-4) modulates the overweightand undernutrition-induced ACE2 downregulation in renal proximal tubule cells: implications for COVID-19? Explor Med. 2021;2:135-45. https://doi.org/10.37349/emed.2021.00038

\section{Abstract}

Aim: The renal lesions-including severe acute kidney injury-are severe outcomes in severe acute respiratory syndrome coronavirus 2 infections. There are no reports regarding the influence of the nutritional status on the severity and progress of these lesions. Ageing is also an important risk factor.

Methods: In the present study we compared the influence of overweight and undernutrition on the levels of renal angiotensin converting enzymes 1 and 2 (ACE and ACE2), which were evaluated by Western blotting. Since the renin-angiotensin-aldosterone system (RAAS) has been implicated in the progress of kidney failure during coronavirus disease 2019, the influence of Angiotensin-(3-4) [Ang-(3-4)] was investigated. Ang-(3-4) is the shortest angiotensin-derived peptide, which is considered the physiological antagonist of several Ang II effects.

Results: Both overweight and undernutrition downregulate the levels of ACE2 without influence on the levels of ACE in proximal tubules from kidney rats. Administration of Ang-(3-4) upregulates ACE2 to levels above the control in overweight but not in undernourished rats.

Conclusions: Chronic undernourishment and overnourishment conditions play a central role in the renal ACE/ACE2 balance, and that the role of RAAS is also different in overweight and undernutrition.

\section{Keywords}

Angiotensin-(3-4), angiotensin converting enzymes 2, COVID-19, overweight and undernutrition, reninangiotensin-aldosterone system

(C) The Author(s) 2021. This is an Open Access article licensed under a Creative Commons Attribution 4.0 International License (https://creativecommons.org/licenses/by/4.0/), which permits unrestricted use, sharing, adaptation, distribution and reproduction in any medium or format, for any purpose, even commercially, as long as you give appropriate credit to the original author(s) and the source, provide a link to the Creative Commons license, and indicate if changes were made. 


\section{Introduction}

Since the first report of coronavirus disease 2019 (COVID-19) in China on 31 December 2019 and isolation of the severe acute respiratory syndrome coronavirus 2 (SARS-CoV-2) virus on January 7, 2020, the number of infections is still growing with an accelerated rate, as well as the number of deaths worldwide [1]. Considering all countries and regions, the number of infections reached $>117$ million people and more than 2,600,000 deaths on March 16, 2021 [2]. Even though the illness was considered a viral infection targeting the respiratory system [3], some cases developed into septic shock [4, 5], in which acute kidney injury (AKI) plays a central role [6]. Age, cancer, cardiovascular diseases and metabolic diseases-such as diabetes-are currently considered the main risk factors for the explosive outbreak of the pandemic [7]. Even though some studies have demonstrated an increased risk for infected patients with renal lesions [8,9], pre-renal mechanisms for AKI-and progression to chronic lesions-must be considered besides the direct interaction of the virus with ACE2. Likely, reduction of blood and $\mathrm{O}_{2}$ supply aggravate kidney lesions during COVID-19 infection.

With respect to the kidney, it is important to remember that angiotensin converting enzyme 2 (ACE2), which is the receptor for the entrance of SARS-CoV-2 into cells $[10,11]$, is highly expressed in the membranes of proximal tubule cells [12], the tubular segment especially affected in AKI [13]. ACE2 is a $92 \mathrm{kDa} \mathrm{Zn}$ metalloprotease [14, 15] that catalyzes the conversion of Ang I in Ang-(1-9) and the generation of Ang-(1-7) from Ang II $[16,17]$. Due to its great abundance in heart and kidneys, it was early considered as a key regulator of the local renin-angiotensin-system (RAS) resident in these organs [15]. As a part of the ACE2/Ang-(1-7)/ Ang-(1-7) receptor (Mas) axis, ACE2 antagonizes the ACE/Ang II/angiotensin type 1 receptor (AT ${ }_{1} \mathrm{R}$ ) axis [18].

Levels of ACE2 seem to be important during COVID-19 infections, and this has been reviewed recently in terms of an apparent paradox demonstrating friend-and-foe roles in the evolution of the viral infection [19]. The friend side is exemplified by the decrease in the proinflammatory Ang II when it is hydrolyzed to Ang-(1-7). However it was also demonstrated that binding of SARS-CoV-2 to ACE2 activates the ACE/ Ang II/AT ${ }_{1}$ R axis triggering the cytokines storm [20]. From a historical and epidemiological perspective, it is important to mention that ACE2 has been described as a receptor for the SARS coronavirus at the beginning of the century [21], indicating that both viruses share the same mechanism in the first step of cell invasion.

ACE is another Zn-metalloprotease that catalyzes the proteolysis of Ang I to Ang II and, therefore, the enzyme that feeds downstream the ACE/Ang II/AT ${ }_{1} \mathrm{R}$ axis within the RAS. The metalloprotease catalytic domains of ACE2 are identical $[14,15]$ and comparison of their genomes suggests that the two genes resulted from duplication [15]. Two isoforms have been described, membrane-bound and soluble, and the main function is attributed to the membrane-bound form, including in kidney [22, 23]. The ACE/ACE2 imbalanceat least in lung and heart-has been proposed to be critical for the outcome of COVID-19 infection [24]. With respect to the kidney, the balance between the two enzymes is considered a key parameter for the regulation of the local RAAS [25] and also for the renal impairment during SARS-CoV-2 infection [26].

The levels of ACE2 decrease with ageing in different tissues [27, 28], but there are no reports regarding the influence of the nutritional status on these levels, especially in obesity and undernutrition, which, as recently emphasized, are considered comorbidities for high risk of unfavorable outcomes [29, 30] and, therefore, must be taken into account to investigate the impact of COVID-19 [29]. The experiments with overweight and undernourished rats were conducted and presented together with data from normonourished juvenile and adult rats, thus allowing comparisons aiming to shed some light on the potential mechanisms underlying the progression, the severity and the outcomes of renal lesions due to COVID-19.

\section{Materials and methods}

\section{Materials}

Monoclonal primary antibodies against ACE (ab11734) and ACE2 (ab108252) were purchased from Abcam (Cambridge, UK). Monoclonal primary antibody against $\beta$-actin (A5441) was purchased from Sigma-Aldrich (Saint Louis, MO, USA). The secondary immunoglobulin G (IgG) anti-mouse (NA931) antibody was also purchased from Sigma-Aldrich. The proteins on Western blotting assays were detected by chemiluminescence 
using the LuminataTM horseradish peroxidase (HRP) reagent (WBLUF0500), which was purchased from Merck Millipore Co. (Darmstadt, Germany).

\section{Diets and experimental groups}

In this study we report the effect of a chronic administration of 2 different diets on the levels of ACE2 in the external portion of rat renal cortex (cortex corticis), where $>95 \%$ of the cell population consists of the proximal tubules [31]. One was a deficient diet that provokes undernutrition, mimicking the alimentary habits of different regions from developing countries, the so-called regional basic diet (RBD) [32], which is characterized by low protein content (also of poor quality), associated with low lipid content, and absence of vitamins and mineral supplementation. The other diet had high lipid (HL) and low carbohydrate content, with an average of $50 \%$ higher $\mathrm{NaCl}$ than the control (CTR) diet (HL diet) [33], that leads to obesity with an elevated deposition of visceral fat, a tissue with high levels of inflammatory factors [34] that can stimulate the renin-angiotensin-aldosterone system (RAAS) [35, 36].

Male Wistar rats were fed: (i) with the RBD from weaning (28 days of age) until 90 days of age (i.e. 62 days); or (ii): with the HL diet from 56 to 162 days of age (i.e. 106 days). The CTR groups received a commercial chow for rodents. At the end of the periods of exposure to the different diets, the rats received Angiotensin-(3-4) [Ang-(3-4)], one oral dose ( $80 \mathrm{mg} / \mathrm{kg}$ body mass) $24 \mathrm{~h}$ before sacrifice in the undernutrition study, and 4 doses at $12 \mathrm{~h}$ intervals from $48 \mathrm{~h}$ before sacrifice in the overweight study. Ang-(3-4) (valine-tyrosine, Val-Tyr), the shortest angiotensins-derived peptide [37, 38], can be viewed as a physiological antagonist of Angiotensin II (Ang II) effects [39]. An enriched plasma membrane fraction from renal cortex corticis (proximal tubule cells) was obtained as previously described [40].

The undernourished and overweight groups originally belonged to different experimental designs using rats, which became hypertensive with stable values of systolic blood pressure at the end of the exposure to diets. The criterion for the use of different doses of Ang-(3-4) was the response of the arterial pressure, which returned to control values with a single administration in the undernourished rats, as well as in the case of spontaneously hypertensive rats [41]. With overweight rats, four doses of Ang-(3-4) were required for the normalization of blood pressure and urinary $\mathrm{Na}^{+}$excretion [42].

Ang-(3-4) was demonstrated to exert its systemic, antihypertensive effects when administered orally in spontaneously hypertensive rats [38, 41] and humans [43], because it is well absorbed when orally administered due to its resistance to hydrolysis and to its high capacity to permeate intestinal cells [44]. Renal accumulation of Ang-(3-4) was observed after a single oral administration and its levels were higher than in other tissues and plasma [45] and, since $\mathrm{AT}_{1} \mathrm{R}$ and $\mathrm{AT}_{2} \mathrm{R}$ are localized in luminal and basolateral membranes [46], the very small Ang-(3-4) can reach and provide a signal from both sides of the proximal tubule cells.

\section{Sodium dodecyl sulphate-polyacrylamide gel electrophoresis (SDS-PAGE) and immunoblotting}

These membrane preparations ( $80 \mu \mathrm{g}$ protein) were used in the SDS-PAGE (10\% acrylamide) and Western blotting assays following electrophoresis as described by Laemmli [47]. Initial suspensions were mixed with a solution containing: dithiothreitol 3.85\% (w/v), SDS 5\% (w/v), Tris- $\mathrm{HCl} 0.2 \mathrm{M}(\mathrm{pH} 6.8)$, glycerol 2.5\% $(\mathrm{v} / \mathrm{v})$, traces of bromophenol blue enough for a proper viewing of the bands, and $\beta$-mercaptoethanol $0.05 \%$ ( $\mathrm{v} / \mathrm{v}, 2$ vol protein suspension: $1 \mathrm{vol}$ solution). The samples were separated (60 mA per gel for approximately $60 \mathrm{~min}$ ) and transferred to nitrocellulose membranes (350 $\mathrm{mA}$ for $90 \mathrm{~min}$ on ice). The blotted membranes were blocked using 5\% non-fat milk diluted in tris-buffered saline plus tween 20 (TBST) [20 mM Tris-HCl (pH 7.4), $150 \mathrm{mM} \mathrm{NaCl}, 0.1 \%$ Tween $20(\mathrm{v} / \mathrm{v})$ ] during $60 \mathrm{~min}$ and then incubated overnight with the specific diluted antibodies (with TBST): 1:100 for ACE and 1:500 for ACE2. $\beta$-actin (dilution: 1:1,000) was used as loading control. After washing with TBST, the blots were developed after 60 min incubation with anti-mouse (1:5,000 for ACE, ACE2 and $\beta$-actin) IgG horseradish peroxidase-conjugated antibodies. After a new washing with TBST the bands were detected using a chemiluminescence imaging system (ImageQuant LAS 4000, GE Healthcare Life Sciences, Buckinghamshire, UK) after incubation with an enhanced chemiluminescence kit (LuminataTM HRP reagent). Densitometric analyses were carried out using Image J for Windows (National 
Institutes of Health, Bethesda, MD, USA). Densitometric values were corrected for the corresponding protein loads. Results were expressed as means \pm standard error of the mean (SEM).

It is important to mention that not all the immunoblots were run and scanned at the same time because they correspond to different studies, which were performed with different diets during different periods (62 and 106 days); see above. Details are also presented in the figure legends.

\section{Statistical analyses}

Differences between 2 groups were assessed by using Student's $t$ test. One-way analysis of variance (ANOVA) followed by Bonferroni's test for selected pairs was used for comparisons among 4 groups. Differences were considered significant at $P<0.05$. Statistical analysis and graphs were prepared using GraphPad Prism 6 software (version 6.01, GraphPad Software, Inc., San Diego, CA, USA).

\section{Results}

ACE2 levels decrease with age in CTR rats, in contrast to the outcome with ACE (Figure 1A and B). Juvenile rats are the CTR animals from the undernutrition study and, according to Quinn [48], 90 days of age correspond to 21 human years and 162 days (adult) correspond to 38 human years. In contrast, ACE levels remained unmodified (Figure $1 \mathrm{~A}$ and $\mathrm{C}$ ).
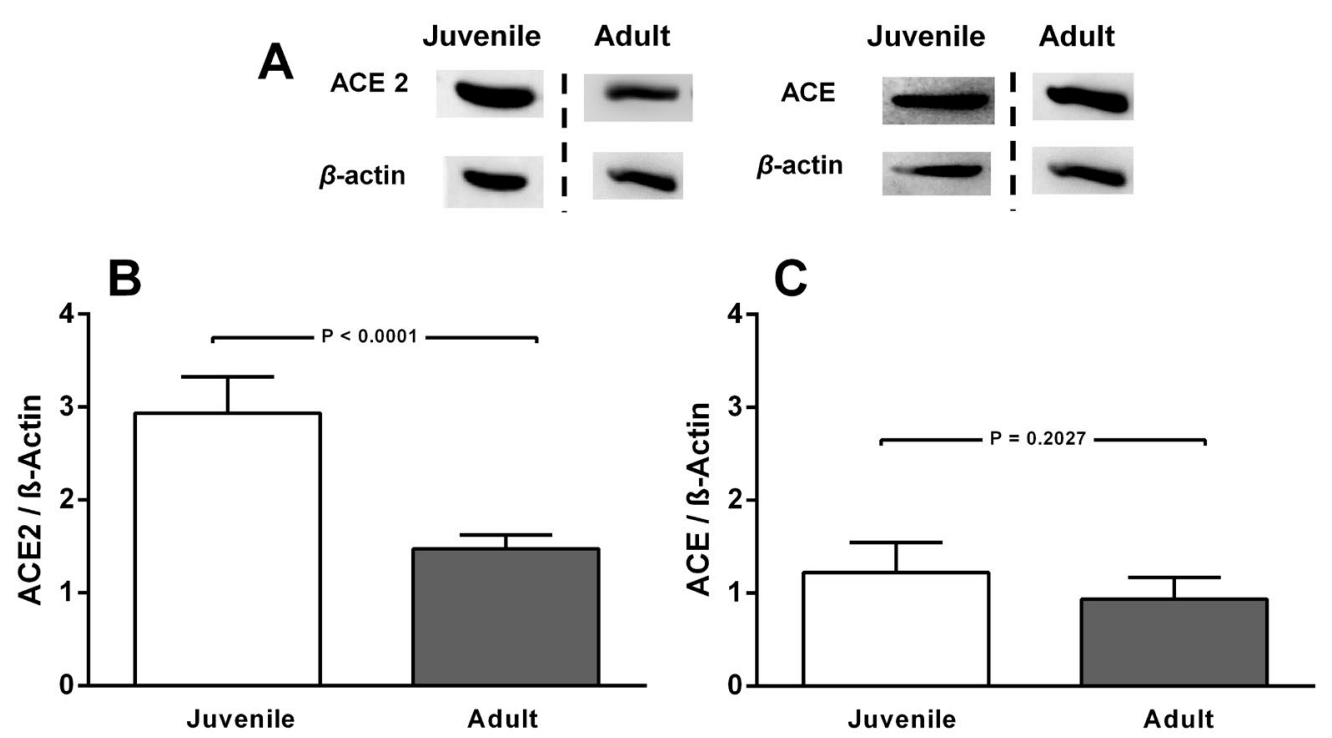

Figure 1. ACE2, but not ACE levels decrease in normonourished CTR rats aged 90 days (juvenile) compared to CTR 162 daysold rats (adult). A. Representative immunoblottings from renal cortex corticis of juvenile and adult rats, with $\beta$-actin as the loading control; B and C. bargraph representation of ACE2 and ACE levels in renal cortex corticis of juvenile and adult rats. Bars indicate mean $\pm \operatorname{SEM}(N=4-8$ different membrane preparations). Statistical differences were estimated by unpaired Student's $t$-test. $P$ values are indicated within the panels. Differences were set at $P<0.05$. In $\mathrm{A}$, the representative blots from juvenile and adult rats were the same for ACE2 and ACE. Cutting was unavoidable because different studies are being compared. They were carried out by using CTR diets along different periods of life. Loading controls were run on the same blot as the representative ACE and ACE2 images. The vertical dashed lines indicate that images come from blots that were run and scanned at different times

The next figures (Figures 2 and 3) show that modifications in the nutritional status profoundly modified ACE2 abundance in the renal cortex corticis, which is also modulated in a different manner by antagonizing RAAS by Ang-(3-4) in cases of overweight or undernutrition. The abundance of ACE2 decreased 30\% in the HL (overweight) rats (Figure 2A and B), whose body mass was $~ 20 \%$ higher than that of the CTR group [42]. Administration of Ang-(3-4) to the overweight rats increased by 75 and 160\%, when the ACE2 levels are compared with those in the CTR and HL rats, respectively, with no influence in the normonourished group. The levels of ACE (Figure 2A and C) remained unmodified either by diet or Ang-(3-4) treatment. 


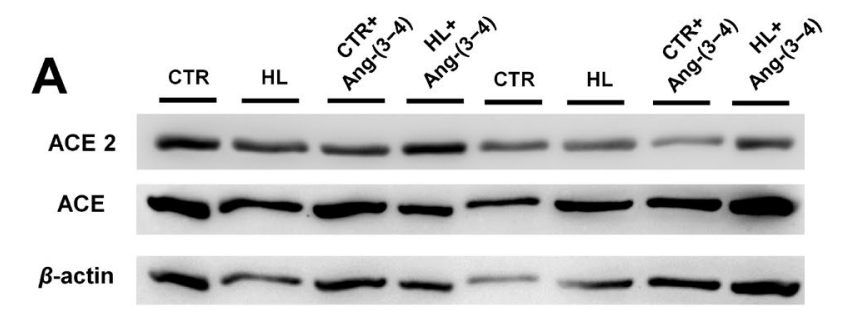

B
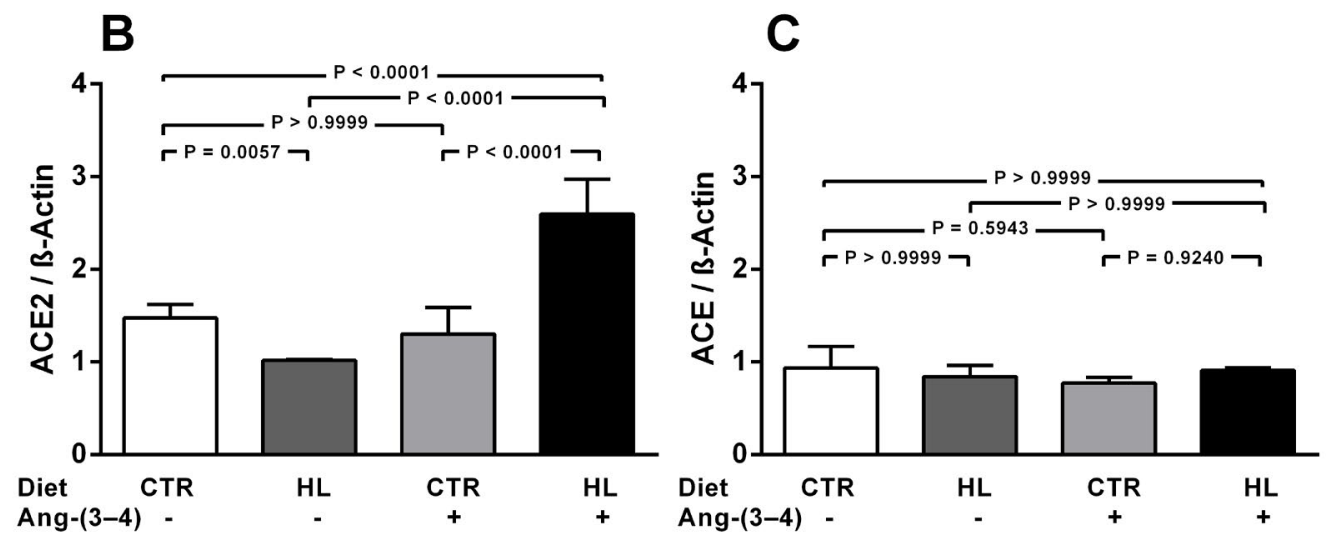

Figure 2. Overweight downregulates $A C E 2$, but not $A C E$, in adult rats on a HL diet. Effects of Ang-(3-4). A. Representative immunoblottings from renal cortex corticis of control and overweight adult rats; $\beta$-actin was used as the loading control; B and C. bargraph representation of ACE2 and ACE levels in renal cortex corticis. Bars indicate mean \pm SEM $(N=4-8$ different membrane preparations). Combinations of diets and Ang-(3-4) administration as indicated above the gel and on the abscissae. Statistical differences were estimated using one-way ANOVA followed by Bonferroni's test for the selected pairs indicated within the panels. Significant differences were set at $P<0.05$. In A, the figure shows bands from the same gel
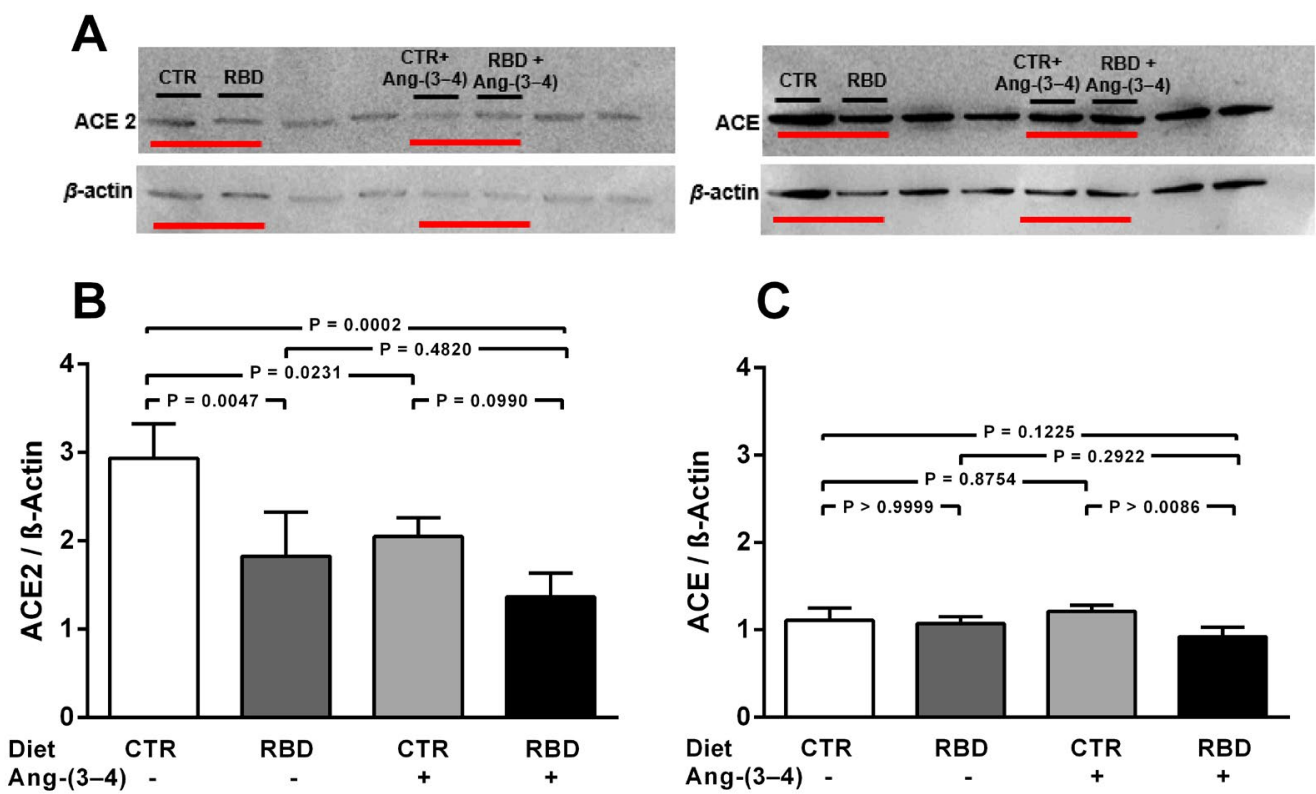

Figure 3. Chronic undernutrition downregulates ACE2, but not ACE, levels in juvenile rats. Effects of Ang-(3-4). A. Representative immunoblottings from renal cortex corticis of juvenile rats; $\beta$-actin was used as loading control; $B$ and $C$. bargraph representation of ACE2 and ACE levels in renal cortex corticis. Bars indicate mean \pm SEM ( $N=4$ different membrane preparations). Combinations of diets and Ang-(3-4) administration as indicated above the representative immunodetections and on the abscissae. Statistical differences were estimated using one-way ANOVA followed by Bonferroni's test for the selected pairs indicated within the panels. Significant differences were set at $P<0.05$. In A, horizontal red lines under bands indicate, in uncropped immunoblottings, the representative immunodetections relative to the present study. The bands not underlined are not related to the work described in this report. Loading controls were run on the same blot as the representative ACE2 and ACE images

The influence of chronic undernutrition on renal ACE2 levels presents some similarity, but also a huge difference, compared with overweight rats (Figure 3). The similarity is in the downregulation of the enzyme level by RBD alone ( $\sim 40 \%$; Figure $3 \mathrm{~A}$ and $\mathrm{B})$, i.e. a value that did not differ from the overweightinduced downregulation seen in Figure $2 \mathrm{~A}$ and $\mathrm{B}(\sim 35 \%)$. In contrast with the effect observed in the case of 
overweight rats, the administration of Ang-(3-4): (i) did not restore (i.e. upregulate) ACE2 in undernourished rats, and (ii) provoked a similar decrease in CTR rats.

\section{Discussion}

The main results described in this study are that Ang-(3-4) per se mimics the effect of undernutrition by downregulating the ACE2 abundance, whereas it upregulates the ACE2 abundance in overweight but not in normonourished rats. They also demonstrate the influence of ageing and nutritional status (overweight and undernutrition), as well as the opposite effects of Ang-(3-4) in the renal ACE2 levels in overweight and undernourished rats. The decrease in ACE2 in this short period of life (Figure 1A and B) may represent an increased the risk of kidney proximal tubule damage during SARS-CoV-2 infection in normonourished rats. ACE levels remained unmodified over that relatively long period of life (Figure $1 \mathrm{~A}$ and $\mathrm{C}$ ) and, therefore, this could contribute to the ACE/ACE2 imbalance that would worsen kidney injuries, as is the case with lung and heart [24], especially in the presence of comorbidities or modifications in the renal local RAAS.

The observations presented in Figure 2 support the view that, in overweight animals, antagonizing the Ang II/AT ${ }_{1}$ R axis by Ang-(3-4) might avoid adverse renal injury in SARS-CoV-2 infections. Recently, Lanza et al. [26] proposed that the RAAS imbalance is central in the pathophysiology of COVID-19. The effect of Ang(3-4) implies that, beyond upregulation of the ACE/Ang II/AT ${ }_{1}$ R axis, intrarenal RAAS can be counteractedin the case of obesity/overweight-by the end product of a pathway that involves progressively shorter Ang II-derived peptides, as we demonstrated a decade ago [49]. The hypothesis of ACE/ACE2 imbalance within the renal RAAS [26] in underlying adverse effects of ageing and nutritional status, however, should be considered speculative at the present stage of this study and requires further investigation, notably looking for possible lesions.

The mechanism underlying the effect of Ang-(3-4) in overweight rats might reflect its action as an "allosteric enhancer" that induces a second binding site in $\mathrm{AT}_{2} \mathrm{R}$ with a very high affinity for Ang II [50], possibly involved in the modulation of ACE2 formation but not of ACE. Another possibility would be a beneficial formation of heterodimers involving these modified $\mathrm{AT}_{2} \mathrm{R}$ and Mas receptors, which would be able to act on ACE2, as in the case of blood pressure [51]. That Ang-(3-4)-mediated upregulation of renal ACE2 occurred in overweight rats, but not in the CTR group, is indicative that a "pro-hypertensive tissular microenvironment" (high Ang II) [41] develops in animals fed with a diet rich in lipids, causing downregulation of ACE2 (Figure $2 \mathrm{~A}$ and $\mathrm{B}$ ) and kidney injury during a SARS-CoV-2 attack.

Again, it may be that activation of the Ang II/AT ${ }_{1} \mathrm{R}$ axis now in a "pro-hypertensive tissular microenvironment" induced by the multideficient diet contributes to the notable decrease in ACE2, and, since there was no modification in ACE (Figure 3A and C), to the important ACE/ACE2 imbalance in proximal tubules that might be crucial in the kidney, as seems to be the case in the lung [24]. On this account, we also have strong evidence for the existence of a "pro-hypertensive tissular microenvironment" in chronically undernourished rats: the increased number of Ang II-positive cells in the tubulointerstitium [52] leads to an increase of the local RAAS.

The observation that Ang-(3-4) administration per se mimics the influence of undernutrition in downregulating ACE2 abundance is consistent with the supposition that $\mathrm{AT}_{2} \mathrm{R}$ acts in parallel with $\mathrm{AT}_{1} \mathrm{R}$ in promoting tissular damage in kidney tissue, as recently reviewed [24]. There is a possibility of an adjuvant and independent $\mathrm{AT}_{2} \mathrm{R}$-associated pathway that, being altered by an amino acid imbalance [53] due to undernutrition, downregulates ACE2 synthesis and levels. A second possibility is the formation of heterodimers between $\mathrm{AT}_{1} \mathrm{R}$ and abnormal $\mathrm{AT}_{2} \mathrm{R}$, which could be modulated by Ang II and Ang-(3-4), as in the case of spontaneously hypertensive rats [41]. As noted above, these rats are of a juvenile age. Therefore, undernutrition may favor severe kidney lesions in young people affected by COVID-19, an issue that has not been explored so far.

In conclusion, our evidence is that overweight and undernutrition favor downregulation of the ACE2 level in proximal tubule cells, being a threat during the clinical evolution of the SARS-CoV-2 infection. However, it must be emphasized that, besides the of ACE/ACE2 imbalance, external mechanisms can contribute to 
the progression of renal lesions: undernutrition and overnutrition provoke local and systemic inflammation that may exacerbate the progression of the renal COVID-19 lesions [20, 30]. The results demonstrate that counteracting RAAS by Ang-(3-4) administration influences ACE2 synthesis in an opposite way in overweight and undernourished rats, indicating different underlying mechanisms, which could modify the type and severity of renal outcomes during SARS-CoV-2 infection.

\section{Limitation of this study}

ACE and ACE2 were analyzed by Western blotting. Quantifying the activity of these enzymes would be desirable to reinforce the significance of the changes described in the present study. Histopathological studies of renal lesions are also needed.

\section{Abbreviations}

ACE: angiotensin converting enzyme 1

ACE2: angiotensin converting enzyme 2

AKI: acute kidney injury

Ang II: angiotensin II

Ang-(3-4): angiotensin-(3-4)

ANOVA: analysis of variance

AT1R: angiotensin II type 1 receptor

AT2R: angiotensin II type 2 receptor

COVID-19: coronavirus disease 2019

CTR: control

HL: high lipid

RAAS: renin-angiotensin-aldosterone system

RBD: regional basic diet

SARS-CoV-2: severe acute respiratory syndrome coronavirus 2

SDS: sodium dodecyl sulphate

SEM: standard error of the mean

TBST: tris-buffered saline plus tween 20

\section{Declarations}

\section{Acknowledgments}

The excellent technical assistance of Gloria Costa-Sarmento and Danilo Bezerra is acknowledged. The authors also acknowledge the English corrections by BioMedES UK and by Dr. Martha Sorenson (Federal University of Rio de Janeiro, Brazil).

\section{Author contributions}

RL, HMF, APA and AV contributed conception and design of the study; RL, HMF, APA, TC and AV organized the data, performed the statistical analysis, wrote the first draft of the manuscript. All authors contributed to manuscript revision, read and approved the submitted version.

\section{Conflicts of interest}

The authors declare that they have no conflicts of interest.

\section{Ethical approval}

The protocols were approved by the Committee for Ethics in Animal Experimentation from the Federal University of Rio de Janeiro (\#101/16 and \#012/19). 


\section{Consent to participate}

Not applicable.

Consent to publication

Not applicable.

\section{Availability of data and materials}

The data that support the findings of this study are available from the corresponding author (AV) upon reasonable request.

\section{Funding}

This work was supported by grants and fellowships from the Brazilian National Research Council (CNPq, 307605/2015-9, 401816/2016-8 and 132666/2019-7), the Carlos Chagas Rio de Janeiro State Foundation (FAPERJ, E-26/202.963/2017, E-26/201.721/2017 and E-26/201.558/2018), the Brazilian Federal Agency for Support and Evaluation of Graduate Education (CAPES, 88887.374390/2019-00) and the National Institute of Science and Technology for Regenerative Medicine/REGENERA 465656/2014-5 (coordinator: Antonio Carlos Campos de Carvalho). The funders had no role in study design, data collection and analysis, decision to publish, or preparation of the manuscript.

\section{Copyright}

(C) The Author(s) 2021.

\section{References}

1. Novel coronavirus-China [Internet]. World Health Organization; c2020 [Cited 2021 Mar 16]. Available from: https://www.who.int/csr/don/12-january-2020-novel-coronavirus-china/en/

2. COVID-19 situation update worldwide [Internet]. European Union: European Centre for Disease Prevention and Control; c2020 [Cited 2021 Mar 16]. Available from: https://www.ecdc.europa.eu/en/ geographical-distribution-2019-ncov-cases

3. Xie P, Ma W, Tang H, Liu D. Severe COVID-19: a review of recent progress with a look toward the future. Front Public Health. 2020;8:189.

4. Hantoushzadeh S, Norooznezhad AH. Possible cause of inflammatory storm and septic shock in patients diagnosed with (COVID-19). Arch Med Res. 2020;51:347-8.

5. Robba C, Battaglini D, Pelosi P, Rocco PRM. Multiple organ dysfunction in SARS-CoV-2: MODS-CoV-2. Expert Rev Respir Med. 2020;14:865-8.

6. Perico L, Benigni A, Remuzzi G. Should COVID-19 concern nephrologists? Why and to what extent? The emerging impasse of angiotensin blockade. Nephron. 2020;144:213-21.

7. Jordan RE, Adab P, Cheng KK. COVID-19: risk factors for severe disease and death. BMJ. 2020;368:m1198.

8. Erpicum P, Grosch S, Bouquegneau A, Huart J, Résimont G, Bovy C, et al. Kidney injury in Covid-19 (Article in French: Atteintes rénales de la COVID-19). Rev Med Liège. 2020;75:109-14.

9. Ferlicot S, Jamme M, Gaillard F, Oniszczuk J, Couturier A, May O, et al. The spectrum of kidney biopsies in hospitalized patients with COVID-19, acute kidney injury, and/or proteinuria. Nephrol Dial Transplant. 2021:gfab042.

10. Hoffmann M, Kleine-Weber H, Schroeder S, Krüger N, Herrler T, Erichsen S, et al. SARS-CoV-2 cell entry depends on ACE2 and TMPRSS2 and is blocked by a clinically proven protease inhibitor. Cell. 2020;181:271-80.e8.

11. Walls AC, Park YJ, Tortorici MA, Wall A, McGuire AT, Veesler D. Structure. function. and antigenicity of the SARS-CoV-2 spike glycoprotein. Cell. 2020;181:281-92.e6. 
12. Ye M, Wysocki J, William J, Soler MJ, Cokic I, Batlle D. Glomerular localization and expression of angiotensin-converting enzyme 2 and angiotensin-converting enzyme: implications for albuminuria in diabetes. J Am Soc Nephrol. 2006;17:3067-75.

13. Bianco M, Lopes JA, Beiral HJV, Filho JDD, Frankenfeld SP, Fortunato RS, et al. The contralateral kidney presents with impaired mitochondrial functions and disrupted redox homeostasis after 14 days of unilateral ureteral obstruction in mice. PLoS One. 2019;14:e0218986.

14. Tipnis SR, Hooper NM, Hyde R, Karran E, Christie G, Turner AJ. A human homolog of angiotensinconverting enzyme. Cloning and functional expression as a captopril-insensitive carboxypeptidase. J Biol Chem. 2000;275:33238-43.

15. Donoghue M, Hsieh F, Baronas E, Godbout K, Gosselin M, Stagliano N, et al. A novel angiotensinconverting enzyme-related carboxypeptidase (ACE2) converts angiotensin I to angiotensin 1-9. Circ Res. 2000;87:E1-9.

16. Vickers C, Hales P, Kaushik V, Dick L, Gavin J, Tang J, et al. Hydrolysis of biological peptides by human angiotensin-converting enzyme-related carboxypeptidase. J Biol Chem. 2002;277:14838-43.

17. Rice GI, Thomas DA, Grant PJ, Turner AJ, Hooper NM. Evaluation of angiotensin-converting enzyme (ACE), its homologue ACE2 and neprilysin in angiotensin peptide metabolism. Biochem J. 2004;383:45-51.

18. Lelis DF, Freitas DF, Machado AS, Crespo TS, Santos SHS. Angiotensin-(1-7), adipokines and inflammation. Metabolism. 2019;95:36-45.

19. Verdecchia P, Cavallini C, Spanevello A, Angeli F. The pivotal link between ACE2 deficiency and SARSCoV-2 infection. Eur J Intern Med. 2020;76:14-20.

20. Mahmudpour M, Roozbeh J, Keshavarz M, Farrokhi S, Nabipour I. COVID-19 cytokine storm: the anger of inflammation. Cytokine. 2020;133:155151.

21. Li W, Moore MJ, Vasilieva N, Sui J, Wong SK, Berne MA, et al. Angiotensin-converting enzyme 2 is a functional receptor for the SARS coronavirus. Nature. 2003;426:450-4.

22. Igić R, Behnia R. Properties and distribution of angiotensin I converting enzyme. Curr Pharm Des. 2003;9:697-706.

23. Igić R, Škrbić R. The renin-angiotensin system and its blockers. Srp Arh Celok Lek. 2014;142:756-63.

24. Sriram K, Insel PA. A hypothesis for pathobiology and treatment of COVID-19: the centrality of ACE1/ ACE2 imbalance. Br J Pharmacol. 2020;177:4825-44.

25. Mizuiri S, Ohashi Y. ACE and ACE2 in kidney disease. World J Nephrol. 2015;4:74-82.

26. Lanza K, Perez LG, Costa LB, Cordeiro TM, Palmeira VA, Ribeiro VT, et al. COVID-19: the renin-angiotensin system imbalance hypothesis. Clin Sci. 2020;134:1259-64.

27. Xie X, Chen J, Wang X, Zhang F, Liu Y. Age- and gender-related difference of ACE2 expression in rat lung. Life Sci. 2006;78:2166-71.

28. Yoon HE, Kim EN, Kim MY, Lim JH, Jang IA, Ban TH, et al. Age-associated changes in the vascular reninangiotensin system in mice. Oxid Med Cell Longev. 2016;2016:6731093.

29. Puig-Domingo M, Marazuela M, Giustina A. COVID-19 and endocrine diseases. A statement from the European Society of Endocrinology. Endocrine. 2020;68:2-5.

30. Morais AHA, Aquino JS, da Silva-Maia JK, Vale SHL, Maciel BLL, Passos TS. Nutritional status, diet and viral respiratory infections: perspectives for severe acute respiratory syndrome coronavirus 2 . Br J Nutr. 2021;125:851-2.

31. Whittembury G, Proverbio F. Two modes of Na extrusion in cells from guinea pig kidney cortex slices. Pflügers Arch. 1970;316:1-25.

32. Teodósio NR, Lago ES, Romani AS, Guedes RCA. A regional basic diet from northeast Brazil as a dietary model of experimental malnutrition. Arch Latinoam Nutr. 1990;40:533-47. 
33. Roberts CK, Vaziri ND, Liang KH, Barnard RJ. Reversibility of chronic experimental syndrome X by diet modification. Hypertension. 2001;37:1323-8.

34. Costa RM, Neves KB, Tostes RC, Lobato NS. Perivascular adipose tissue as a relevant fat depot for cardiovascular risk in obesity. Front Physiol. 2018;9:253.

35. Francischetti EA, Genelhu VA. Obesity-hypertension: an ongoing pandemic. Int J Clin Pract. 2007;61: 269-80.

36. Hall JE, do Carmo JM, da Silva AA, Wang Z, Hall ME. Obesity-induced hypertension: interaction of neurohumoral and renal mechanisms. Circ Res. 2015;116:991-1006.

37. Matsufuji H, Matsui T, Seki E, Osajima K, Nakashima M, Osajima Y. Angiotensin I-converting enzyme inhibitory peptides in an alkaline protease hydrolyzate derived from sardine muscle. Biosci Biotechnol Biochem. 1994;58:2244-5.

38. Saito Y, Wanezaki K, Kawato A, Imayasu S. Antihypertensive effects of peptide in sake and its by-products on spontaneously hypertensive rats. Biosci Biotechnol Biochem. 1994;58:812-6.

39. Dias J, Axelband F, Lara LS, Muzi-Filho H, Vieyra A. Is angiotensin-(3-4) (Val-Tyr). the shortest angiotensin II-derived peptide. opening new vistas on the renin-angiotensin system? J Renin Angiotensin Aldosterone Syst. 2017;18:1470320316689338.

40. Vieyra A, Nachbin L, de Dios-Abad E, Goldfeld M, Meyer-Fernandes JR, de Moraes L. Comparison between calcium transport and adenosine triphosphatase activity in membrane vesicles derived from rabbit kidney proximal tubules. J Biol Chem. 1986;261:4247-55.

41. Dias J, Ferrão FM, Axelband F, Carmona AK, Lara LS, Vieyra A. ANG-(3-4) inhibits renal Na+-ATPase in hypertensive rats through a mechanism that involves dissociation of ANG II receptors, heterodimers, and PKA. Am J Physiol Renal Physiol. 2014;306:F855-63.

42. Luzes R, Crisóstomo T, Silva PA, Iack R, de Abreu VG, Francischetti EA, et al. Angiotensin-(3-4) normalizes blood pressure, decreases $\mathrm{Na}+$ and energy intake, but preserves urinary $\mathrm{Na}+$ excretion in overweight hypertensive rats. Biochim Biophys Acta Mol Bas Dis. 2021;1867:166012.

43. Kawasaki T, Seki E, Osajima K, Yoshida M, Asada K, Matsui T, et al. Antihypertensive effect of valyltyrosine, a short chain peptide derived from sardine muscle hydrolyzate, on mild hypertensive subjects. J Hum Hypertens. 2000;14:519-23.

44. Pentzien AK, Meisel H. Transepithelial transport and stability in blood serum of angiotensin-I-converting enzyme inhibitory dipeptides. Z Naturforsch C J Biosci. 2008;63:451-9.

45. Matsui T, Imamura M, Oka H, Osajima K, Kimoto KI, Kawasaki T, etal. Tissue distribution of antihypertensive dipeptide, Val-Tyr, after its single oral administration to spontaneously hypertensive rats. J Pept Sci. 2004;10:535-45.

46. Imig JD, Navar LG. Measurement of renal tubular angiotensin II. Methods Mol Med. 2001;51:427-34.

47. Laemmli UK. Cleavage of structural proteins during the assembly of the head of bacteriophage T4. Nature. 1970;227:680-5.

48. Quinn R. Comparing rat's to human's age: how old is my rat in people years? Nutrition. 2005;21:775-7.

49. Axelband F, Dias J, Miranda F, Ferrão FM, Barros NM, Carmona AK, et al. A scrutiny of the biochemical pathways from Ang II to Ang-(3-4) in renal basolateral membranes. Regul Pept. 2009;158:47-56.

50. Axelband F, Dias J, Miranda F, Ferrão FM, Reis RI, Costa-Neto CM, et al. Angiotensin-(3-4) counteracts the Angiotensin II inhibitory action on renal Ca2+-ATPase through a cAMP/PKA pathway. Regul Pept. 2012;177:27-34.

51. Patel S, Hussain T. Dimerization of AT2 and Mas receptors in control of blood pressure. Curr Hypertens Rep. 2018;20:41. 
52. Silva PA, Muzi-Filho H, Pereira-Acácio A, Dias J, Martins JFS, Landim-Vieira M, et al. Altered signaling pathways linked to angiotensin II underpin the upregulation of renal $\mathrm{Na}^{+}$-ATPase in chronically undernourished rats. Biochim Biophys Acta. 2014;1842:2357-66.

53. Harper AE, Benevenga NJ, Wohlhueter RM. Effects of ingestion of disproportionate amounts of amino acids. Physiol Rev. 1970;50:428-558. 